\section{Response to "Clarification from the College of Physicians and Surgeons of BC on commentary about limitations of the CDC guideline for prescribing opioids"}

We appreciate Dr. Oetter's feedback ${ }^{1}$ on our commentary. ${ }^{2}$ The announcement by the College of Physicians and Surgeons of British Columbia regarding their new prescribing standards states:

Many of the principles contained in the new standard reflect the US Centers for Disease Control and Prevention's (CDC) Guideline for Prescribing Opioids for Chronic Pain - United States 2016, which the Board endorsed in April 2016. ${ }^{3}$

The college's fourth standard (https:// www.cpsbc.ca/files/pdf/PSG-Safe-Prescrib ing.pdf), also a recommendation by the CDC guideline, directs physicians to prescribe opioids at doses not exceeding $90 \mathrm{mg}$ of morphine or equivalent (MME) per day except in cases of "exceptional need and benefit," excluding treatment with methadone.

With no clear definition of what constitutes exceptional need and benefit, a physician might abruptly reduce prescribed doses simply to comply with this regulatory standard. A survey conducted by the Boston Globe and Inspire, an American health care social network of 200 online support groups with 800000 members, found that nearly two-thirds of respondents reported that acquiring prescribed opioid medication had become more difficult in the past year. When asked why, 26\% advised that their doctors had stopped prescribing opioids and another 15\% reported that their physicians had decreased their doses. ${ }^{4}$

Some patients will find withdrawal from opioids to be intolerable and one option to mitigate symptoms is to seek illicit opioids. Maria Hudspith, executive director of Pain BC, has reported that her organization is hearing from concerned pain sufferers who no longer have access to opioids, and are turning to the streets to acquire them. ${ }^{5}$

Notwithstanding Dr. Oetter's point regarding the flexibility allowed a physician based on his or her judgment, we believe that more specific guidance is needed to guard against harms associated with opioid reduction and withdrawal, particularly for patients using high-dose opioids. We submit for consideration our ninth draft recommendation from the updated Canadian guideline for opioids and chronic non-cancer pain (currently available for public review and comment: http://nationalpaincentre. mcmaster.ca).

Recommendation \#9: For patients with chronic non-cancer pain currently using $90 \mathrm{mg}$ morphine equivalents of opioids per day or more, we suggest tapering opioids to the lowest possible dose, including discontinuation, rather than no change in opioid therapy (Weak recommendation, Low quality evidence).

Associated remark: Some patients are likely to experience significant increase in pain or decrease in function that persist more than one month after a small dose reduction; tapering may be paused and potentially abandoned in such patients.

Associated rationale: Reduction in opioid dose may reduce adverse effects including cognitive impairment and the likelihood of nonfatal or fatal unintentional overdose. Reduction, particularly if not done very slowly, may cause increased pain, decreased function, or highly aversive symptoms of opioid withdrawal.

We encourage the College of Physicians and Surgeons of British Columbia to consider expanding its standards to provide explicit guidance of this sort, including the option for tapering to be paused or abandoned based on a patient's response.

\section{Jason W. Busse DC PhD}

Michael G. DeGroote Institute for Pain

Research and Care, Departments of

Anesthesia and Health Research Methods, Evidence and Impact, McMaster

University, Hamilton, Ont.

\section{David Juurlink MD PhD}

Departments of Medicine and Paediatrics, University of Toronto, Toronto, Ont.

\section{Gordon H. Guyatt MD MSc}

Department of Health Research Methods, Evidence and Impact, McMaster University, Hamilton, Ont.

Cite as: CMAJ 2017 April 3;189:E509. doi: $10.1503 / \mathrm{cmaj} .732910$

\section{References}

1. Oetter HM. Clarification from the College of Physicians and Surgeons of BC on commentary about limitations of the CDC guideline for prescribing opioids [letter]. CMAJ 2017;189:E508.

2. Busse JW, Juurlink D, Guyatt GH. Addressing the limitations of the CDC guideline for prescribing opioids for chronic noncancer pain. CMAJ 2016; 188:1210-1.

3. College Board adopts new professional standard on safe prescribing to address public health emergency related to opioid overdoses [media release]. Vancouver: College of Physicians and Surgeons of British Columbia; 2016 June 1. Available: https://www.cpsbc.ca/ files/pdf/2016-06-01-Board-Adopts-New-Standard -on-Safe-Prescribing.pdf (accessed 2017 Feb. 11).

4. Freyer FJ. Strict opioids laws hit chronic pain sufferers hard. Boston Globe and Inspire 2016 June 16. Available: https://www.bostonglobe. com/metro/2016/06/18/the-other-side-america -war-opioids/i9YYLR0bGWFdP9z1T1pwjl/story. html (accessed 2017 Feb. 11).

5. Meuse M. Pain sufferers turning to street drugs as B.C. doctors prescribe fewer opioids. CBC News 2016 July 19. Available: www.cbc.ca/news/canada/ british-columbia/opioid-prescriptionreluctance-1 .3685377 (accessed 2017 Feb. 11).

Competing interests: All of the authors are members of the guideline development group for the Canadian Guideline for Safe and Effective Use of Opioids for Chronic Non-Cancer Pain. David Juurlink was a member of the Stakeholder Review Group for the CDC Guideline for Prescribing Opioids for Chronic Pain. No other competing interests were declared. 